\title{
A EDUCOMUNICAÇÃ O, como um campo de intervenção social e de investigação acadêmica
}

\section{EDUCOMMUNICATION as a field of social intervention and academic investigation, by Ismar Soares}

\author{
Ismar SOARES ${ }^{1}$
}

Ao longo da primeira década do século XXI, o professor Ismar Soares colaborou para que o conceito da educomunicação fosse adotado por projetos e políticas em níveis municipal, estadual e federal, promovendo novas formas de uso da mídia nos processos educativos. Destes, se destacam o "Educom.TV", de 2002, primeiro curso a distância implementado pela USP em parceria com a SE/SP; o "Educom.rádio", projeto que levou a educomunicação para 455 escolas da cidade de São Paulo; e o curso a distância "Mídias na Educação", do MEC, implementado desde 2006 em São Paulo, em uma parceria entre a UFPE e o NCE, já tendo formado 7 mil professores. Nesta breve entrevista, ele fala à Revista Mídia e Cotidiano sobre o campo da educação para as mídias e a contribuição educomunicativa à educação híbrida conectada.

Throughout the first decade of the 21st century, professor Ismar Soares has contributed for the adoption of the concept of educommunication by projects and policies at the city, state and federal levels, promoting news ways of media use within educational processes. A few examples of these are represented by "Educom.TV", the first distance learning course, which was launched in 2002 and implemented by USP in a partnership with SE/SP; "Educom.rádio", a project which has managed to bring educommunication to 455 schools in the city of São Paulo, and "Mídias na Educação", (Media in Education), The Ministry of Education's (MEC) long distance course, which started in 2006 in São Paulo as a result of a partnership between UFPE and NCE. 7 thousand teachers have now completed this last course. In this short interview, he speaks with the Media and Cotidiano (Media and Everyday Life) Journal about the field of media educommunication as well as about educommunication's contribution for a connected hybrid education.

\footnotetext{
${ }^{1}$ Iniciou no ensino superior na Faculdade de Comunicação da Universidade Metodista, em São Bernardo do Campo, em 1974. Doutor em Ciências da Comunicação, pela ECA/USP (1986), fez pós-doutorado junto à Marquette University, Milwaukee, WI, USA (1999-2000). Professor Titular da ECA/USP, chefiou o Departamento de Comunicações e Artes por 8 anos, em dois mandatos. Fundou, na ECA, o NCE Núcleo de Comunicações e Artes, tendo coordenado, entre 1997-1999, a pesquisa que definiu e sistematizou o conceito da educomunicação, como um campo de intervenção social e de investigação acadêmica na interface comunicação/educação. Atualmente, coordena a Licenciatura em Educomunicação da ECA/USP.
} 
$\boldsymbol{R M C}$ - $O$ senhor é um dos pioneiros dos estudos mídia e educação na América Latina, e criador do conceito educomunicação. Como o senhor avalia a evolução das práticas educomunicativas nas escolas brasileiras?

Ismar - A primeira iniciativa coletiva com a qual me envolvi foi o Projeto de Leitura Crítica Comunicação, nos anos de 1980 e 1990, promovido pela UCBC União Cristã Brasileira de Comunicação Social, entidade ecumênica que defendia a liberdade de expressão nos tempos duros da ditadura e que foi responsável por uma intensa atividade de análise da mídia, em encontros para jovens e lideranças populares.

No final dos anos de 1990, já na Universidade de São Paulo, interessei-me por saber o que o movimento em torno da educação para a comunicação representava no contexto das transformações sociais pelas quais passava a América Latina. Foi quando identifiquei, numa pesquisa junto a especialistas de 12 países do continente, que a herança de resistência cultural latinoamericana havia propiciado a formação um pensamento próprio sobre as relações entre o mundo da educação o universo da comunicação. Para além do olhar vigilante dos educadores sobre o trabalho dos meios de informação, vinha se consolidando a perspectiva de que comunicar é um bem em si mesmo e um direito a ser conquistado.

A este movimento cultural, a pesquisa aplicou o neologismo Educomunicação, cujo conceito central é o da gestão compartilhada da comunicação, transferindo o protagonismo do agir comunicativo dos sistemas impessoais, economicamente dependente do grande capital, aos sujeitos sociais, especialmente às crianças e jovens.

No caso, a Educomunicação passou a ser uma aliada dos promotores da educação midiática, garantindo referenciais e metodologias de ação. Pessoalmente, testemunhei que as dificuldades que tinha, no início de meu 
trabalho, em motivar colégios, professores e estudantes a adotar procedimentos voltados para a educação midiática, eram rapidamente superadas quando os educadores passavam a trabalhar com o paradigma educomunicativo.

A primeira grande experiência de aproximação entre o novo conceito e as políticas de educação deu-se no espaço de 450 escolas públicas do município de São Paulo, num projeto extracurricular, implantado entre 2001 e 2004, pelo Núcleo de Comunicação e Educação da USP (NCE/USP), destinado a combater a violência nas escolas, a partir de um movimento em torno da melhoria das relações comunicativas entre os agentes vivos do ecossistema comunicativo das escolas. Onze mil entre professores, alunos e membros das comunidades educativas compartilharam da formação. Passados 15 anos, a Educomunicação - amparada por uma lei aprovada pela câmara municipal em dezembro de 2004 - segue vigente na capital paulista.

Experiências semelhantes ocorrem Brasil a fora, envolvendo, em numerosos casos, a colaboração de organizações sociais. É o que podemos verificar no Programa Mais Educação, do Governo Federal, que adota o paradigma da Educomunicação para o tratamento dos projetos relacionados à comunicação e ao uso de mídias, implantados em mais de seis mil escolas, favorecendo um total aproximado de dois milhões e meio de estudantes. Para que isso ocorra, monitores vinculados a ONGs que trabalham com mídia e criança/jovens são chamados a oferecer sua colaboração, como oficineiros.

Nesta linha, mais recentemente, em novembro de 2015, o Colégio Dante Alighieri, uma das mais prestigiadas escolas da iniciativa privada da capital paulista, reformou um de seus ônibus escolares para convertê-lo em estúdio móvel para reforçar a prática educomunicativa de seus alunos, em diálogo aberto com a cidade e seus problemas ${ }^{2}$.

\footnotetext{
${ }^{2}$ http://www.abpeducom.org.br/2015/11/educom-avanca-no-dante-alighieri.html.
} 
Tais exemplos mostram que a Educomunicação vem avançando com segurança desde a sistematização do conceito, em 1999, contando, hoje, com mais de 140 teses defendidas em 18 centros de pós-graduação do país. A criação de uma associação nacional de educomunicadores ${ }^{3}$ vem fortalecer este caminho.

$\boldsymbol{R M C}$ - Comunicação e educação. De que forma a educomunicação se aproxima do crescente uso das novas tecnologias na educação híbrida e conectada?

Ismar - Em relação às tecnologias, ninguém nega que já estejamos imersos na era digital. Um esforço educacional não formal, mas sempre ativo e abrangente, garante o acesso crescente a celulares e a outros dispositivos digitais, para o lazer até mesmo de segmentos com pouco acesso à escola.

Não se pode dizer que as políticas públicas de educação estejam desatentas à imperiosa necessidade de ampliar o acesso aos novos recursos. O problema é que a orquestração em favor das tecnologias no ensino não chega a sensibilizar as instituições formadoras de pedagogos e licenciados. Pesquisa recente, defendida junto à Faculdade de Educação da USP, informa que, em média, as faculdades de educação do Estado de São Paulo não destinam mais do que $2,5 \%$ de suas grades curriculares ao tema das tecnologias educativas. Como consequência, os docentes têm pouco a contribuir para mudanças nas políticas educacionais relacionadas ao emprego das novas ferramentas. As inovações ficam por conta de projetos pioneiros, de iniciativa de organizações sociais específicas, sem que se tenha garantia de que as práticas que ganham luminosidade venham transformar-se em política pública, em condições de beneficiar todo o sistema de ensino.

O que diferencia o pensamento educomunicativo nesse tópico é sua visão de que as TIC não apenas cheguem às escolas, mas que lá sejam acolhidas como

\footnotetext{
${ }^{3}$ www.abpeducom.org.br.
} 
recursos indispensáveis para o fortalecimento de uma aprendizagem coletiva e colaborativa. Não é exatamente a performance individual o que interessa, mas o conhecimento sobre as possibilidades que as tecnologias oferecem para a mobilização da comunidade escolar em torno de temas de interesse coletivo. A título de exemplo, frente a uma proposta de projeto que visa destinar "um computador por aluno", a Educomunicação prefere um projeto que instale um laboratório de multimeios, em cada unidade escolar, para uso solidário e compartilhado de professores e alunos.

O próprio laboratório de informática educativa, quando implantado a partir da perspectiva educomunicativa, pode servir a outros fins que não à tradicional aprendizagem sobre o manuseio dos equipamentos. É o que tem sido observado mais recentemente nas redes de ensino que optam pelo uso dos recursos digitais de uma forma colaborativa, acoplando-os a programas que envolvem o estudo de temas relacionados às práticas de cidadania.

Para a Educomunicação não existem, na verdade, hierarquias tecnológicas, que diferenciem as mais novas das mais antigas. Quanto foi para combater a violência nas escolas de São Paulo, o recurso escolhido foi a linguagem radiofônica, apresentada em seu suporte analógico, e não exatamente a última geração de suportes digitais. O que importava, na ocasião, era possibilitar que alunos e professores descobrissem seu potencial de trabalhar em equipe e de mixar suas vozes, seus sons e seus sonhos, com as vozes, sons e sonhos dos habitantes do ecossistema comunicativo da escola e de seu entorno. No caso de São Paulo, ao longo dos últimos 15 anos, do analógico passou-se muito rapidamente ao digital, sem que se perdesse a graça da produção coletiva, agora envolvendo tanto as crianças da educação infantil, quanto os adolescentes finalistas do nono ano do ensino fundamental ${ }^{4}$.

\footnotetext{
${ }^{4}$ http://portal.sme.prefeitura.sp.gov.br/Main/Page/PortalSMESP/Nas-Ondas-do-Radio.
} 
$\boldsymbol{R M C}$ - A educomunicação preconiza o empoderamento do aluno a partir da apropriação e uso dos meios nos ambientes de ensino e aprendizagem. A leitura crítica dos meios continua sendo relevante neste processo?

Ismar - $\mathrm{O}$ empoderamento das crianças e jovens tanto para a produção quanto para a recepção crítica da mídia tem mobilizado organizações sociais em todo o Brasil. É com carinho e entusiasmo que lembramos, por exemplo, de experiências como a implementada pela Fundação Casa Grande, em Nova Olinda ${ }^{5}$, transformada em "escola de comunicação para a meninada do sertão". Servem de referências, igualmente, projetos como o da instituição Planetapontocom ${ }^{6}$, com sede no Rio de Janeiro, mobilizado práticas de midiaeducação em todo o Brasil, e da ONG Viração ${ }^{7}$, que a partir de sua sede em São Paulo articula núcleos de jovens repórteres em 25 estados da federação, construindo colaborativamente uma revista de circulação nacional e mantendo uma agência de notícias, através da qual promovem coberturas educomunicativas de eventos nacionais e internacionais.

Sonhamos que o privilégio que beneficia as crianças e jovens atendidos por estas organizações seja compartilhado com os 40 milhões de crianças e jovens das escolas brasileiras. Esta é a expectativa da própria UNESCO que vem trabalhando intensamente para que o direito à comunicação chegue às políticas de ensino, através de programas de alfabetização midiática e informacional adaptados às sucessivas fases do desenvolvimento do ensino nas escolas de todos os países do mundo ${ }^{8}$.

\footnotetext{
${ }^{5}$ www.fundacaocasagrande.org.br.

${ }^{6}$ planetapontocom.org.br.

${ }^{7}$ www.viracao.org.

${ }^{8}$ http://unesdoc.unesco.org/images/0022/002204/220418por.pdf.
} 
É importante lembrar que para a UNESCO, assim como para as instituições referendadas, a produção midiática e a recepção crítica caminham juntas. É o que vem acontecendo com a experiência educomunicativa do Colégio Dante Alighieri: enquanto inaugurava seu estúdio móvel de produção audiovisual, um grupo de estudantes lançava um E-book onde relatavam suas experiências de produção midiática e de análise crítica dos meios de comunicação.

Na verdade, o protagonismo da ação comunicativa associada à reflexão sobre o comportamento da mídia é o que aproxima, colaborativamente, o pensamento educomunicativo das práticas preconizadas pela área da Midiaeducação. 